\title{
Integration of Infrared Thermography in O\&M Activities
}

\section{Introduction}

Infrared thermography is a method, which detects infrared energy emitted from object, converts it to temperature, and displays image of temperature. It captures as a temperature distribution on a surface, and it can display as a visible information. Temperature can be measured from a distance without contacting an object. Temperature can be measured in real time.

\section{Advantages of thermography}

Thermography is used in many fields, some of the advantages are listed below

- It shows a visual picture of temperatures over a large area which can be compared

- It is capable of catching moving targets in real time

- It is able to find deteriorating, i.e., higher temperature components prior to their failure

- It can be used to find defects in shafts, pipes, and other metal or plastic parts. It can be used to detect objects in dark areas

- It has medical applications as well.

\section{Applications}

Thermography is used in almost all fields, listed are the few of the applications.

- Condition monitoring

- Thermal Mapping

- Digital infrared thermal imaging in health care

- Night vision and Targeting

- Nondestructive testing

- Surveillance in security, law enforcement and defense

\section{Abstract}

Tata power has License for Generation, Transmission \& Distribution. Tata power is having its presence across the globe. Tata Power - Mumbai Distribution is spread across the geographies.

The assets of Tata Power are

\begin{tabular}{|l|l|l|}
\hline Description & Voltage levels (kV) & Numbers \\
\hline Receiving Station & $220 / 110$ & 19 \\
\hline Distribution Sub Station & $33 / 11$ & 29 \\
\hline Consumer Sub Station & $11 / 0.433$ & 700 \\
\hline
\end{tabular}

There are equivalent no's of associated HT and LT Equipment's, Distribution and Power Transformers in the CSS and DSS. It is imperative that these above equipment's shall run at all the times.

In order to ensure the reliability of electrical power delivery while reducing cost, it is necessary to monitor the condition of critical equipment installed in the substations. 
Infrared Thermography has significant impact in predetermining the early stage of faults and predict failures by avoiding forced outages.

\section{Application of Infrared Thermography in TATA Power:}

1) The periodic infrared thermography of the existing assets gives us idea on thermal behavior of the components of the electrical system.

Base data is collected by carrying out the thermos scanning of the critical equipment's. Thermo Scanning is carried out periodically $\&$ the temperatures recorded are compared with the base temperatures. Any equipment located with the higher temperature (beyond the acceptable values) are identified \& necessary action is initiated. Thus avoiding the force outages.

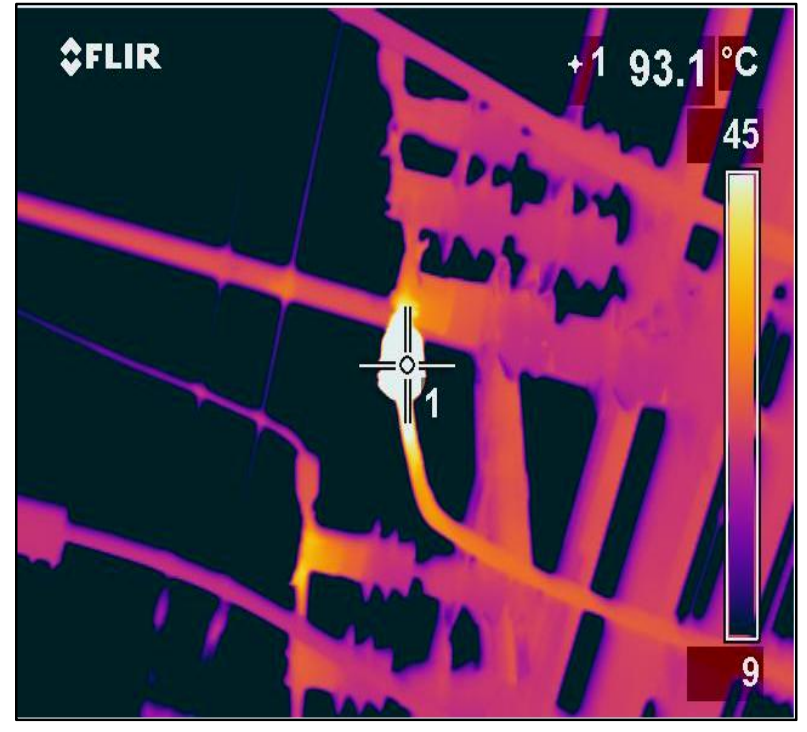

Hot-spot located on the jumpers in Receiving Station

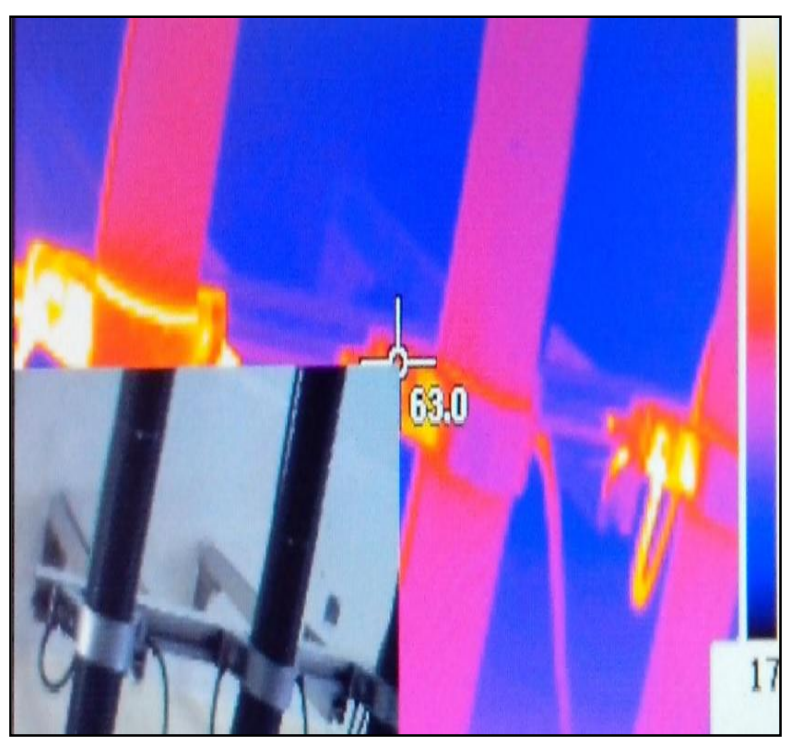

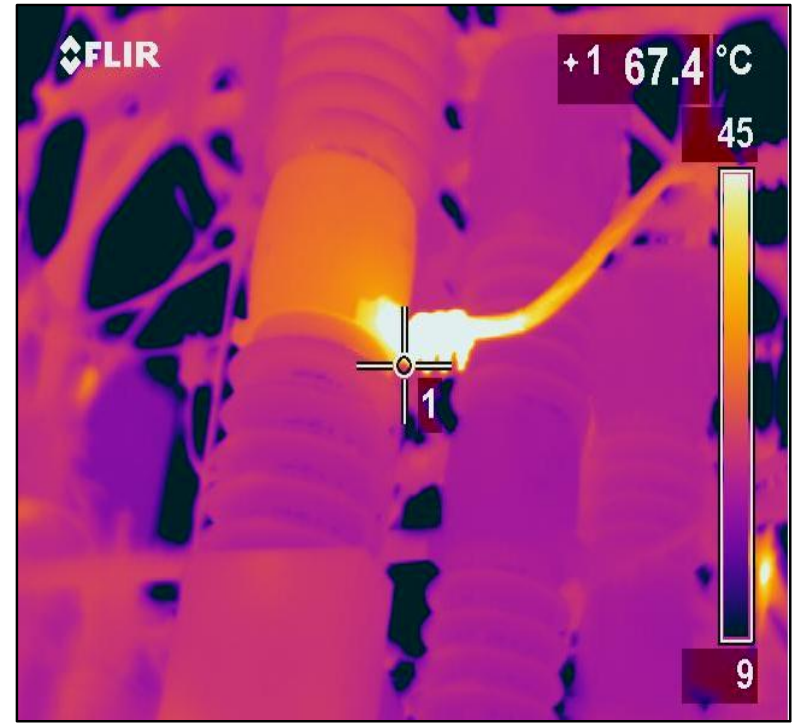

Hot-spot located on the breaker connections in Receiving Station

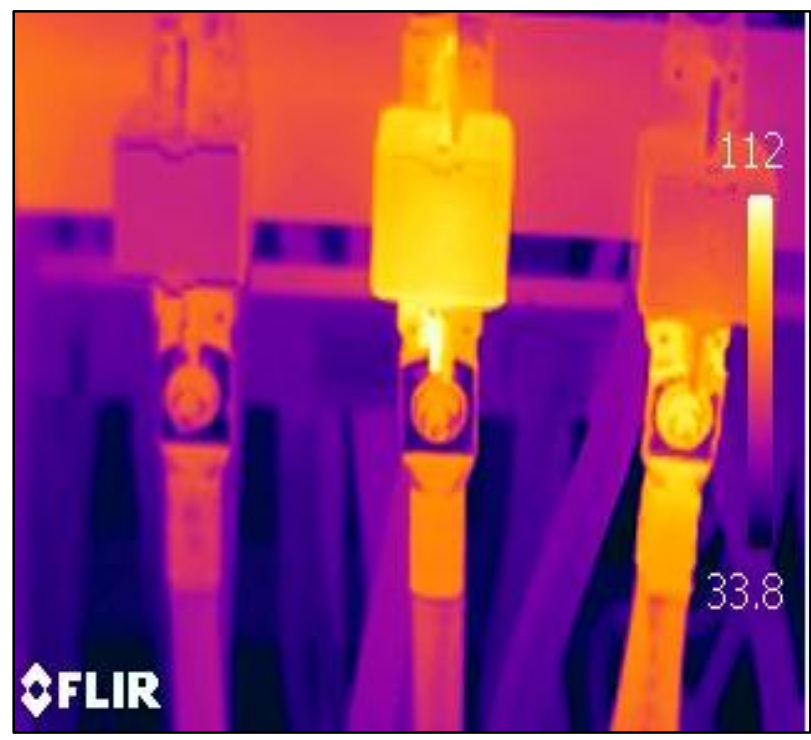

Hot-spot on LT Panel 
2) TATA Power has proactively initiated the infrared thermography of Power and Distribution Transformers during Type Test for determining the temperature rise by imposing the $100 \%$ overloading condition at OEM factory.

The temperature rise above ambient condition for each equipment is being specified as per the technical specification.

Recently 20-25MVA Ester Filled Transformer has been inspected at Schneider Factory at Baroda during Heat Run Test at $100 \%$ and $120 \%$ overloading to ensure enhanced capacity utilization.

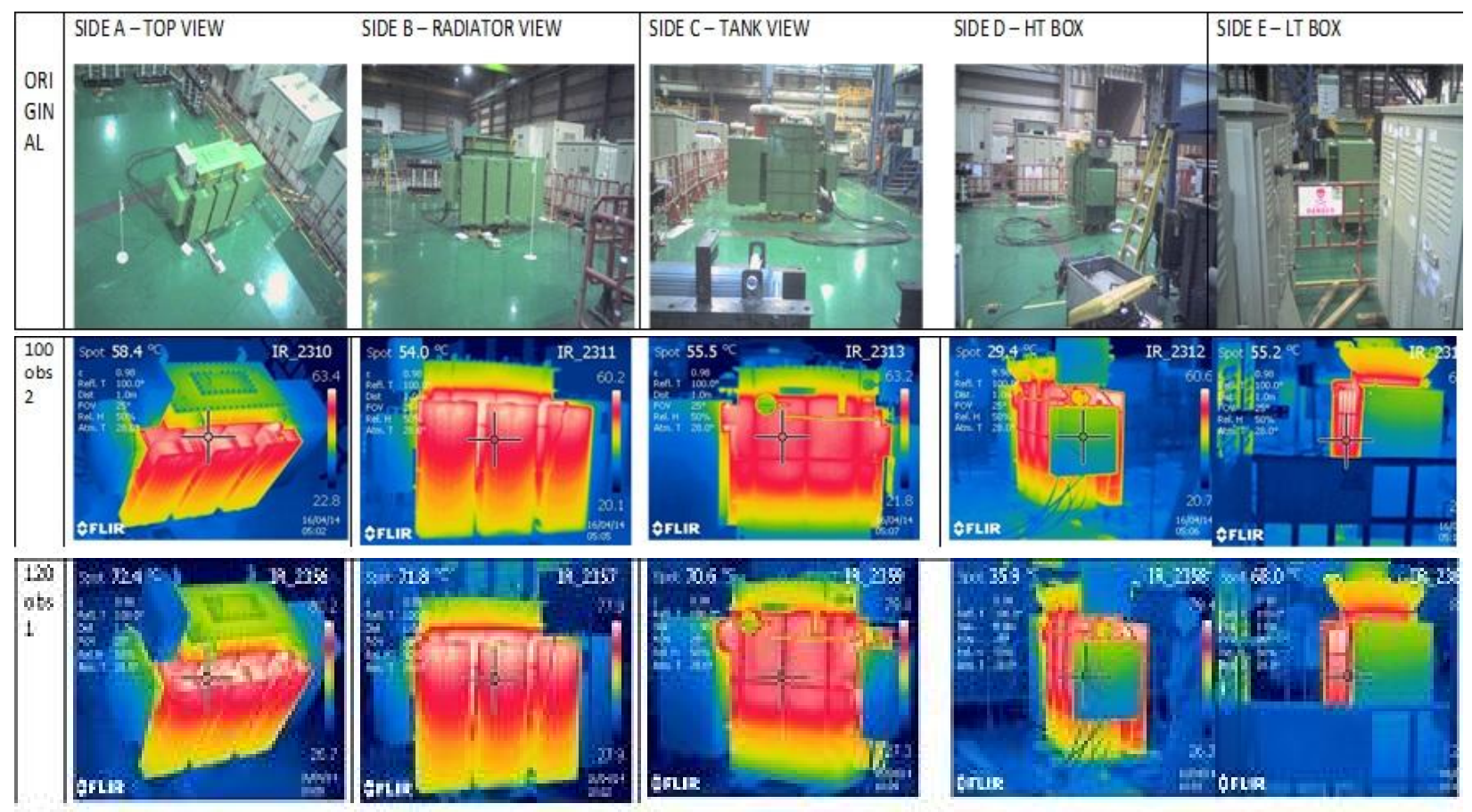

3) Online monitoring of the critical equipment's by installation of Infrared Thermograph Camera at one of TATA Power DSS.

\section{Conclusion:}

1) The Infrared Thermography is one of tools for determining the predetermine faults in the existing equipment's, leading to enhanced reliability and saving in cost associated with forced outages

2) The introduction of Infrared Thermography at OEM side, during equipment specific type test has enabled us to ensure the quality of the equipment delivered.

3) Online monitoring of assets and vigilance at unmanned stations situated in remote locations is possible.

4) Infrared Windows for continuous monitoring of the bus is being introduced. 